Revista lus et Praxis, Año 25, № 2, 2019, pp. 189 - 222

ISSN 0717 - 2877

Universidad de Talca - Facultad de Ciencias Jurídicas y Sociales

La no equivalencia funcional entre la prueba electrónica y la prueba documental:

Una lectura desde la regulación procesal colombiana

Ángel Francisco Galvis Lugo - Mónica Bustamante Rúa

Trabajo recibido el 26 de junio de 2018 y aprobado el 8 de enero de 2019

\title{
La no equivalencia funcional entre la prueba electrónica y la prueba documental: Una lectura desde la regulación procesal colombiana*
}

\author{
THE NO FUNCTIONAL EQUIVALENCE BETWEEN THE \\ ELECTRONIC PROOF AND THE DOCUMENTARY PROOF: A READING \\ FROM THE COLOMBIAN PROCEDURAL REGULATION
}

\author{
Ángel Francisco Galvis Lugo** \\ MÓnica Bustamante Rúa**
}

\begin{abstract}
Resumen
El principio de equivalencia funcional se constituyó en el vehículo para que la prueba electrónica pudiera ser ingresada al proceso civil con plenos efectos de eficacia y validez a fin de que el juez del conocimiento la admitiera y valorara según el estándar establecido para la prueba documental. Sin embargo, la prueba electrónica dista en gran medida de la prueba documental, lo que pone en duda la veracidad de este principio de equivalencia funcional y, a su vez, la efectividad de la prueba electrónica en el juicio civil.
\end{abstract}

\section{ABSTRACT}

The principle of functional equivalence constituted the vehicle so that the electronic proof could be entered into the civil trial with full efficacy and validity effects in order that the judge of civil process would admit them and evaluate them according to the standard established for the documentary proof. However, the electronic proof is far distance from the documentary proof, questioning severely the veracity of this principle of functional equivalence, and in turn, the effectiveness of the electronic proof in the civil trial.

\footnotetext{
* El artículo es producto de la tesis doctoral títulada "Articulación entre la regulación legal del mensaje de datos como medio de prueba en el juicio civil y el postulado de tutela judicial efectiva desde la posibilidad de su reconfiguración bajo la categoría de prueba electrónica como medio de prueba autónomo", desarrollada por Ángel Francisco Galvis bajo la dirección de tesis de Mónica Bustamante.

** Abogado de la Universidad Libre Seccional Pereira, especialista en Derecho Procesal Civil de la Universidad Externado de Colombia, especialista en Derecho Procesal Contemporáneo de la Universidad de Medellín, magíster en Derecho Procesal de la Universidad de Medellín. Aspirante a doctor en Derecho Procesal Contemporáneo de la Universidad de Medellín. Correo electrónico: angelfgalvis@gmail.com.

*** Abogada y magíster en Derecho Procesal de la Universidad de Medellín, Colombia. Doctora en derecho y magíster en Derecho Procesal de la Universidad Nacional del Rosario, Argentina. Directora del doctorado en Derecho Procesal Contemporáneo y jefa del programa de maestría en Derecho Procesal Contemporáneo de la Universidad de Medellín. Integrante del grupo de investigaciones en Derecho Procesal UDEM categoría A Colciencias. Correo electrónico: mmbustamante@udem.edu.co.
} 
Palabras Clave

Equivalencia funcional, prueba electrónica, prueba documental

KEY WORDS

Functional equivalence, electronic proof, documentary proof

\section{Introducción}

"Idem est non esse aut non probari" .

Tradicionalmente se ha contemplado que el fin de todo proceso judicial es la obtención de una decisión justa que ponga fin a un conflicto intersubjetivo de intereses, y esa decisión se debe tomar con base en las pruebas legal y oportunamente allegadas al proceso y practicadas dentro del mismo. De allí que la convicción del operador judicial se forme a partir de los medios probatorios que las partes le propongan. Esos medios probatorios no son otra cosa que la representación de la verdad de los hechos, trasladada al escenario jurídico.

Decía el profesor Rocha ${ }^{2}$ que la verdad proviene de tres fuentes: la metafísica, en cuanto a las ideas puras; la verdad física por percepción de los sentidos, y la verdad histórica por las relaciones interpersonales, siendo entonces la inteligencia, los sentidos y las relaciones personales las fuentes del conocimiento. Concordante con lo anterior, plantea Marina Gascón ${ }^{3}$ que "El procedimiento probatorio judicial va encaminado a poder afirmar que ciertos hechos son verdaderos. Pero se hace necesaria una precisión. Tanto el discurso científico como el judicial son discursos lingüísticos, o si se quiere, en ambos casos se pretende afirmar la verdad no de hechos sino de enunciados sobre hechos. En particular, en el discurso judicial los Ilamados 'hechos probados' no son más que enunciados asertivos de lo que se predica de la verdad. Por ello, entre las muchas concepciones de verdad que se han desarrollado a lo largo de la historia, aquí nos interesa la verdad como propiedad de ciertos enunciados".

Pero para trasladar esa verdad, o los enunciados asertivos sobre hechos, al estadio judicial y convertirla en verdad procesal, o verdad probada, se deben cumplir unas etapas sine qua non los enunciados quedarían sin sustento, o, en otras palabras, la representación de los hechos no alcanzaría el estándar de verdad probada dentro del juicio. Ello es conocido como el iter probatorio, que son las etapas que debe superar la prueba judicial hasta llegar en debidos términos al conocimiento del juez, tal como lo conciben autores que manifiestan

\footnotetext{
1 Aforismo romano que traduce "Tanto da no probar como no tener el derecho".

2 Rocha (1990), p. 29.

3 Gascón (2010), p. 50.
} 
que la función de la prueba es precisamente obtener el convencimiento del juzgador acerca de la existencia de algunos hechos ${ }^{4}$. Todo ello bajo la garantía del debido proceso.

En este sentido, el derecho procesal, desde su concepción primigenia, ha evolucionado en cuanto a su contenido, a su objeto de estudio y a su regulación, de manera tal que, de materia reguladora de formas procesales, ha mutado a un sistema garantista, constitucionalizado y humano, cuyo fin es lograr una tutela judicial efectiva que resuelva el conflicto intersubjetivo de intereses de los asociados, conflicto que se soluciona a través de la correcta valoración racional de las pruebas que se practiquen en un juicio con cumplimiento del debido proceso probatorio.

Ahora bien, teniendo en cuenta la evolución de la sociedad en cuanto al uso de las tecnologías de la información, se tiene que se ha generado un nuevo escenario (sociedad de la información) ${ }^{5}$, en donde surgen y se plantean conflictos intersubjetivos de intereses, como consecuencia del uso de las tecnologías de la información.

Y la verdad de los hechos de esos conflictos está inmersa en pruebas electrónicas, que se deberán llevar al escenario judicial en aras de resolver efectivamente, con las garantías constitucionales propias, los conflictos que surjan en este plano informático.

Y para garantizar lo anterior, al momento de llevar esas pruebas electrónicas al escenario judicial, la regulación, generalizada en América Latina por provenir de una misma fuente ${ }^{6}$ y recogida en la legislación colombiana ${ }^{7}$, indica que no se puede restar efectos jurídicos a la información que esté en forma de mensaje de datos.

Aunque en un principio esta disposición fuera concebida como la panacea jurídica respecto a una nueva fuente de prueba, o fuentes de dimensión paralegal ${ }^{8}$, una vez en el proceso civil, la prueba electrónica sufre una transformación, pues no existe este medio de prueba como tal dentro de la legislación procesal civil colombiana, de manera que para ingresarla al proceso se debe revestir de otro medio de prueba, ya que el mensaje de datos es regulado como un documento ${ }^{9}$, y tal mutación, por Ilamarla de alguna manera, se efectúa en

\footnotetext{
4 Palomo (2007), p. 186.

${ }^{5}$ Davara (2008), pp. 26, 498.

${ }^{6}$ Ley Modelo de la Cnudmi sobre Comercio Electrónico, de 1996.

7 Ley $N^{\circ} 527$, de 1999, artículo $5^{\circ}$.

${ }^{8}$ Meneses (2008), p. 60.

${ }^{9}$ Ley No 1.564, de 2012, artículos 243 y 247.
} 
virtud del denominado principio de equivalencia funcional. Este, en última instancia, señala que para que el mensaje de datos pueda ingresar al proceso civil, debe ser validado, admitido y valorado según los estándares señalados para la prueba documental ${ }^{10}$, equiparando de esta manera estos dos medios probatorios.

Sin embargo, la prueba electrónica dista significativamente de lo que se conoce como prueba documental, pues tanto en su génesis como en su práctica, su contenido, su traslado al proceso, sus vicisitudes, su apreciación por el juez del conocimiento, etc., se encuentran marcadas diferencias, lo que permite inferir, con alto grado de acierto, que el tratamiento equivalente que la ley otorga a ambos medios de prueba implica que la verdad de los hechos, que en última instancia es lo que persigue la garantía del debido proceso, contenida a su vez en el derecho procesal contemporáneo, no llegue de forma correcta al juez del conocimiento, conllevando que hechos que no ocurrieron puedan ser tenidos como probados, y de la misma manera, hechos que sí ocurrieron puedan ser desechados en un juicio civil, colocando en serios aprietos el cumplimiento del postulado de tutela judicial efectiva, lo que amerita una revisión de este principio de equivalencia funcional, pues, de no ser cierto tal principio, la prueba electrónica requeriría de todo un desarrollo normativo, principialístico y procesal para que la representación de los hechos que ella contiene efectivamente llegue al conocimiento del juzgador, y este, a su vez, pueda tener las herramientas necesarias para proferir una decisión justa que resuelva de forma eficaz el conflicto intersubjetivo de intereses que se le plantea.

En las siguientes líneas, se abordará la prueba documental intentando describirla conceptualmente para luego asumir el estudio de la prueba electrónica desde su génesis hasta su valoración, y a partir de estas dos líneas se elaborará un comparativo que arrojará resultados respecto de si el principio de equivalencia funcional realmente opera para estos dos medios de prueba, con lo cual se podrán formular algunas conclusiones respecto al tema planteado.

\section{La prueba documental}

La verdad material puede ser incorporada al proceso civil a través de varios medios probatorios, siendo el documental el equivalente funcional, por ley, de la prueba electrónica, por lo cual se hará referencia a esta prueba documental en las siguientes líneas.

${ }^{10}$ Ley N N 527, de 1999, artículo 10, señala que "los mensajes de datos serán admisibles como medios de prueba $(\ldots)^{\prime \prime}$. 
El profesor Parra Quijano define el documento como "cualquier cosa que sirva por sí misma para ilustrar o comprobar por vía de representación, la existencia de un hecho cualquiera o la exteriorización de un acto humano"11. De esta definición se destaca el carácter declarativo y/o representativo que incorpora la prueba documental, que de cualquier manera debe estar contenida en un medio físico perceptible a los sentidos. Sin embargo, autores como Michelle Taruffo ${ }^{12}$ afirman que la tendencia que parece imperar en los sistemas del common law y en particular en Estados Unidos es considerar las pruebas documentales no como un tipo especial de prueba, sino como un caso del concepto más amplio de prueba real demostrativa.

Uno de los doctrinantes nacionales en pruebas documentales, el profesor José Fernando Ramírez Gómez ${ }^{13}$, relaciona diez definiciones doctrinarias sobre prueba documental, además de la definición de este medio de prueba en diferentes legislaciones, para luego plasmar el concepto unitario contenido en la legislación colombiana: “(...) todo objeto que teniendo origen en la actividad del hombre puede ser llevado materialmente al proceso con el fin de probar el hecho que representa"14.

De otro lado, no se puede hablar de principios de la prueba documental en estricto sentido, pues es unificado el criterio doctrinal acerca de los principios generales de los medios probatorios, que por ser generales cobijan también a las pruebas electrónicas o mensaje de datos; sin embargo, se pueden identificar algunas diferencias.

De antaño se ha señalado que el documento contiene tres elementos ${ }^{15}$ : la corporalidad (cosa mueble), la subjetividad (el autor) y el contenido (signos de la representación), elementos estos que parecen haber quedado en el pasado frente a las nuevas formas de comunicación entre asociados. Prueba de ello es que la concepción sistemática del documento ha migrado de las escuelas tradicionalistas, que la identificaban con la concepción estructural del documento como representación textual escrita de hechos, a sistemas procesales modernos, que acogen la concepción funcional del documento como medio contentivo de signos del lenguaje indistintamente de su elemento material, dando así cabida a medios probatorios como las cintas, las grabaciones y los mensajes de datos.

11 PARRA (2002), p. 441.

12 TARuffo (2008), p. 76.

13 Ramírez (2008), p. 48.

14 Ramírez (2008), p. 50.

15 Ramírez (2008), p. 53. 
Y es precisamente aquí, bajo esta concepción funcional del documento, que tanto el anterior Código de Procedimiento Civil colombiano como el actual Código General del Proceso ${ }^{16}$ regulan la concepción de documento, siendo obviamente la norma vigente la que se refiere expresamente al mensaje de datos como elemento de prueba y más precisamente como una clase de prueba documental, mas no como medio probatorio, cuyas particularidades se abordarán más adelante. Pero volviendo a lo que se conoce como prueba documental, doctrinaria y académicamente los profesores de la materia abordan el tema desde varias perspectivas, analizando cada uno de los elementos integrantes de tal medio probatorio. El citado Ramírez Gómez ha acogido la concepción gnoseológica del documento, que implica la corporeidad sostenida por Jaime Guasp, la representatividad explicada por autores como Carnelutti y la subjetividad en cuanto a su origen por actividad del hombre.

De la corporeidad se critica el hecho de que como condición física tenga la cualidad de ser trasportado al proceso; ello porque pruebas documentales como las lápidas o los monumentos, mencionadas en el propio ordenamiento procesal civil, no pueden cumplir esta condición de movilidad ${ }^{17}$.

Al tenerse la prueba documental como toda expresión de persona conocida o conocible, se les resta este estándar a los documentos anónimos, de manera tal que este tipo de prueba deberá contener siempre la identificación mediata o inmediata de su autor.

Carnelutti hablaba además del elemento representativo como la sustitución de un hecho por otro a través de la percepción de un objeto. En esta medida, el objeto físico llevado al proceso debe permitir ser percibido de manera tal que pueda sustituir el hecho real dentro del proceso. De ahí el elemento representativo de la prueba documental.

Y, más recientemente, Juan Carlos Riofrío también se ha referido a la clasificación del documento como medio de prueba, retrotrayéndose a conceptos clásicos; así: "La clasificación de los elementos de la prueba es otra cuestión harto debatida. Chiovenda ${ }^{18}$ diferencia como elementos constitutivos de la prueba los

\footnotetext{
16 Ley No 527, de 1999, artículo 243: "Distintas clases de documentos. Son documentos los escritos, impresos, planos, dibujos, cuadros, mensajes de datos, fotografías, cintas cinematográficas, discos, grabaciones magnetofónicas, videograbaciones, radiografías, talones, contraseñas, cupones, etiquetas, sellos y, en general, todo objeto mueble que tenga carácter representativo o declarativo, y las inscripciones en lápidas, monumentos, edificios o similares".

17 Ramírez (2008), p. 53. "De aquí que resulte criticable la presentación que el art. 251 del C. de P. Civil hace de las inscripciones en lápidas, monumentos, edificios o similares como ejemplo de documentos, porque ellas se sustraen al régimen general del documento como cosa transportable al proceso $(\ldots)^{\prime \prime}$.

${ }^{18}$ De PINA (1942), p. 45.
} 
motivos, los medios y los procedimientos. Manzani ${ }^{19}$ habla de fuentes, medios y elementos. Guasp ${ }^{20}$, de elementos, fuentes, medios, motivos, materias, tema y resultados. Vishninski ${ }^{21}$, simplemente de los hechos que es necesario probar y los hechos que se emplean para probar algo".

Desde otro elemento, y sin entrar en mayores detalles, doctrinalmente los documentos se han clasificado según su origen en públicos y privados; según su forma, en documento público y de simple origen oficial, y escrito y no escrito; por la certeza sobre su autoría, en auténticos y no auténticos; por el contenido, se clasifican en representativos, declarativos y declarativos-representativos; por su función, se clasifican en constitutivos y meramente probatorios, y de acuerdo con su naturaleza se clasifican en originales, duplicados y copias.

De acuerdo con lo explicado por el profesor Ramírez Gómez ${ }^{22}$, además de la anterior clasificación existe otro tipo de clasificación doctrinal que los individualiza en documentos criptográficos, heterógrafos y autógrafos, narrativos y no narrativos, entre otras tantas clasificaciones.

En síntesis, pese a los múltiples criterios de clasificación, de contenido y de acepción, existe una connotación casi generalizada respecto de lo que es prueba documental, tanto doctrinaria como legalmente. Sin embargo, con la inclusión de las tecnologías de la información en la interacción de la sociedad moderna, la teoría de la prueba documental ha estado siendo reconfigurada para admitir otra variedad de documentos ${ }^{23}$, desconocidos hasta hace poco más de una década, pero que actualmente representan el instrumento de mayor uso $^{24}$ en áreas como la comercial, que precisamente fue la que dio pie para que las Naciones Unidas profiriera la ya renombrada Ley Modelo sobre Comercio Electrónico.

\section{Génesis y desarrollo de la prueba electrónica}

Claude Shannon ${ }^{25}$, considerado como el padre y fundador de la era de las comunicaciones electrónicas desde los años 40, fue la primera persona en

\footnotetext{
19 MANZINI (1952), p. 208.

20 Guasp (1998), p. 301.

${ }^{21}$ VISHINSKI (1951), p. 252.

22 Véase Ramírez (2008), p. 48.

${ }^{23}$ LLUCh y Picó I JunOr (2011), p. 27.

${ }^{24}$ Cano (2010), p. 104: "cada año se envían en todo el mundo más de 2.8 trillones de correos electrónicos y, en la actualidad, más del $90 \%$ de los documentos que se crean en la organización son ya electrónicos, de los cuales menos del 30 \% Ilegan a imprimirse en papel".

${ }_{25}$ New York University (en línea).
} 
referirse al término "informática", describiéndola como todo aquello que está presente en un mensaje o señal cuando se establece un proceso de comunicación entre un emisor y un receptor. Sin embargo, hay quienes atribuyen este término al francés Philippe Drefus ${ }^{26}$, hacia el año 1962, por la unión de los términos information y automatique.

La Unesco define la informática como la ciencia relacionada con los sistemas de procesamiento de información y sus implicaciones económicas, políticas y socioculturales, mientras que para Miguel Angel Dávara ${ }^{27}$ la informática es "la ciencia del tratamiento automático de la información". Y es que el uso popularizado de esta nueva "informática" ha cambiado ostensiblemente la manera en que las personas se interrelacionan, se comunican y hasta la forma en que desarrollan sus actividades cotidianas, a tal punto que se habla del fenómeno de la globalización como "motor de desnacionalización de los mercados, las leyes y la política" ${ }^{28}$, o como nueva forma de imperialismo y colonización ${ }^{29}$, lo que se potencia con la eliminación de las fronteras que aportó el ciberespacio a la humanidad.

Surgió así entonces la necesidad de regular tales relaciones, para lo cual se requería legislar sobre el tema, y es precisamente de esta necesidad que nació la Lex Mercatoria ${ }^{30}$ como uno de los más grandes ejemplos sobre globalización. Según palabras de Francisco Moreno ${ }^{31}$, es "(...) un Derecho fruto de las necesidades de las relaciones mercantiles mundiales (globalizadas) creado por la clase empresarial/comercial (business community) sin la mediación del poder legislativo de los Estados. Además, no precisa recurrir en su mayor parte de la fuerza coactiva monopolizada por los Estados; se disciplina por las propias reglas uniformes que se generan espontáneamente entre los actores comerciales de los mercados mundiales".

${ }^{26}$ Philippe Drefus, profesor universitario en la Universidad de Harvard y licenciado en Física en el año 1950.

27 Davara (2008), p. 48.

${ }^{28}$ EnRíquez (2008).

29 Piqueras (2008).

30 Moreno explica que antes del surgimiento del moderno Estado regulador se desarrolló un incipiente comercio internacional que fue extendiéndose por buena parte del planeta. Ante esta internacionalización de la actividad mercantil, se produjo espontáneamente un derecho autónomo, libre de interferencias de cualquier gobierno y basado en los usos existentes entre los comerciantes, denominado Lex Mercatoria. Los jueces de los mercaderes, tal y como hacen los modernos arbitrajes, basaban sus resoluciones en el conocimiento que tenían de la costumbre o usos comerciales para la resolución de disputas [MORENO (2008)].

31 Moreno (2008). 
Es así como la Comisión de las Naciones Unidas para el Derecho Mercantil Internacional, en su sesión $N^{\circ} 29$, llevada a cabo en New York entre el 28 de mayo y el 14 de junio de 1996, promulgó la Ley Modelo sobre Comercio Electrónico, que, entre otros asuntos, se ocupó del acceso y uso de los mensajes de datos, del comercio electrónico y de las firmas digitales, de cuyos efectos globalizantes es evidencia su adopción progresiva como legislación interna por un gran número de países iberoamericanos. Entre ellos se cuenta Colombia, que en el año 1999 sancionó la Ley № 527 a imagen y semejanza de la anterior, salvo la tercera parte, referente a los mecanismos de certificación de firmas digitales. Posteriormente, se promulgó la Ley Nº 906, de 31 de agosto de 2004, la cual permite reconocer como documento, entre otros, a los mensajes de datos y las grabaciones computacionales, pero no los define en sentido estricto, razón por la cual la Ley № 527 de 1999 se torna en el eje normativo en Colombia respecto al mensaje de datos y firma digital ${ }^{32}$.

La normativa nacional no hace mención a la prueba electrónica en razón a que la Ley Modelo de Comercio Electrónico de la Uncitral tampoco la menciona, dado que circunscribe al mensaje de datos toda la información generada, enviada, recibida, almacenada o comunicada por medios electrónicos. Sin embargo, doctrinariamente se puede extractar el significado de prueba electrónica, siendo los profesores españoles Xavier Abel Lluch y Joan Picó i Junoy $^{33}$ unos de los mayores expositores del tema y que brindan una definición bastante acertada, precisándola así: “(...) la información obtenida a partir de un dispositivo electrónico o medio digital, el cual sirve para formar la convicción en torno a una afirmación relevante para el proceso. Una fotografía, un video, una página web, un correo electrónico, una base de datos, una contabilidad en un programa de cálculo Excel -por citar algunos ejemplos-, en cualquier soporte (digital, magnético o informático), constituyen una 'prueba electróni$\mathrm{ca}^{\prime}$ o 'documento electrónico', aun cuando su reproducción e impugnación puedan ser diferentes".

Por su parte, Juan Carlos Riofrío define el documento electrónico o digital como "aquel documento soportado en cualquier medio, de tal forma que solo

\footnotetext{
32 Rincón (2015), p. 86: "Firma electrónica son los métodos tales como, códigos, contraseñas, datos biométricos, o claves criptográficas privadas, que permiten identificar a una persona, en relación con un mensaje de datos, siempre y cuando, el mismo sea confiable y apropiado respecto de los fines para los que se utiliza la firma, atendidas todas las demás circunstancias del caso, así como cualquier acuerdo pertinente". Firma digital: "es un valor numérico que se adhiere a un mensaje de datos y que, utilizando un procedimiento matemático conocido, vinculado a la clave del iniciador y al texto del mensaje permite determinar que este valor se ha obtenido exclusivamente con la clave del iniciador y que el mensaje inicial no ha sido modificado después de efectuada la transformación".
}

33 LLUCH y PICó I JunOY (2011), p. 23. 
resulte legible o entendible al ser humano por medio de computadores o aparatos electrónicos" ${ }^{\prime 34}$.

Cabe mencionar que, según este experto ${ }^{35}$, un transmisor, un microprocesador, un enchufe son medios electrónicos que evidentemente carecen del docet, refiriéndose a la intencionalidad y expresividad humana con respecto a la información allí contenida, y de la grafía o firma que identifica su autor, necesarias para constituirse en documento. Agrega que un texto creado inintencionalmente por error en la máquina, aunque aparezca visible en la pantalla en lenguaje informático no puede ser documento, porque le falta esa intencionalidad propia del documento; sin embargo, en nuestro sentir sí podrían encuadrarse en la definición de Xavier Abel en cuanto a prueba electrónica.

Según Riofrío ${ }^{36}$ tampoco sería documento el hardware del computador ni tampoco la bios ${ }^{37}$; no obstante, en el entendido de que estos dispositivos puedan contener información, aunque no se enmarcan en la definición de mensaje de datos de la Ley $N^{\circ} 527 / 99$, sí podrían ser objeto de prueba electrónica como fuente en donde se origine la información o el hecho, que necesariamente deberá ser iniciado por el ser humano, aún en contra de su voluntad, dada la automaticidad de ciertos procesos informáticos ${ }^{38}$.

El artículo $2^{\circ}$ de la Ley $N^{\circ} 527$ de 1999 define el mensaje de datos como "La información generada, enviada, recibida, almacenada o comunicada por medios electrónicos, ópticos o similares, como pudieran ser, entre otros, el Intercambio Electrónico de Datos (EDI), Internet, el correo electrónico, el telegrama, el télex o el telefax". Al respecto, el profesor Jeimy Cano asegura: “(...) no sería adecuado afirmar que sólo los mensajes de datos pueden obrar como prueba en la medida en que otra información consignada en medios informáticos, la cual no constituye documento o mensaje de datos alguno, pueda ofrecer certeza o convencimiento sobre unos hechos determinados" ${ }^{\prime 39}$.

A su vez, el profesor Ramírez Gómez ha manifestado que "La prueba informática puede ser tomada de tres maneras: a) Como presunción o indicio

34 Riofrío (2004), p. 67.

35 Riofrío (2004), p. 37.

36 Riofrío (2004), p. 37.

37 Bıos, "Basic Input-Output System", sistema básico de entrada-salida. Programa incorporado en un chip de la placa base que se encarga de realizar las funciones básicas de manejo y configuración del ordenador [MTEHERAN (2008)].

${ }^{38}$ LLUCH y PICÓ I JunOr (2011), p. 197: "el documento creado por el propio sistema informático y que también se puede almacenar y recuperar (una contabilidad, base de datos, informe, etc.)".

${ }^{39}$ Cano (2010), p. 101. 
(así la presenta Parra Quijano); b) como complemento de prueba escrita, y bajo este tratamiento en consideración a que la prueba no se desnaturaliza cuando para su conocimiento se acude a otros medios, se abre un panorama amplio para ella dentro de las normas vigentes; y c) constituir el comienzo de una prueba escrita" ${ }^{40}$.

Resulta interesante el análisis que hace el profesor José Fernando Ramírez al identificar los documentos electrónicos (mensaje de datos) tal como lo define la Ley $N^{\circ}$ 527/99, diferenciándolos de los documentos informáticos, que a su parecer: "en sentido amplio", son aquellos que reproducen las computadoras $u$ otros aparatos de la informática moderna, pero cuya lectura o comprensión es posible de manera directa, sin auxilio o traducción de máquinas, pensemos en el correo electrónico impreso, en la boleta que expide el cajero bancario, etc., frente a los cuales el régimen probatorio clásico no sufre mayor vicisitud"41.

Por su parte, Gallizia definió el documento electrónico de la siguiente manera: "un objeto físico dirigido a conservar y transmitir informaciones mediante mensajes en lengua natural, realizado con la intermediación de funciones electrónica"42.

En síntesis, prueba informática es aquella producida a través de medios o instrumentos informáticos o telemáticos ${ }^{43}$, contentiva de hechos de la realidad como producto de la interrelación de los justiciables en virtud del uso de las tecnologías de la información, cuya verdad de los hechos puede ser trasladada al plano jurídico al momento de debatir un conflicto intersubjetivo que requiera una decisión judicial. No obstante la disparidad de acepciones ${ }^{44}$ pero igualdad de criterios, como ocurre con cualquier otro medio de prueba, la ley le adjudica unos criterios de admisibilidad, eficacia y validez para ser considerada como tal, mismos que se encuentran en la propia Ley $N^{\circ} 527$ de 1999 y que se pueden sintetizar en el siguiente cuadro, que explica la manera en que el requisito legal de ciertos actos es cumplido por el mensaje de datos en virtud del principio de equivalencia funcional:

\footnotetext{
40 RAMírez (2008), p. 252.

${ }^{41}$ Ramírez (2008), p. 256.

42 BeCERra (2015).

${ }^{43}$ LLUCH y Picó I JunOr (2011), p. 196.

${ }^{44}$ El mensaje de datos como género intenta abarcar la cantidad de medios probatorios generados o contenidos en medios electrónicos, que son designados de varias maneras: prueba electrónica, prueba informática, documento electrónico, documento informático, mensaje multimedia, documento multimedia, etc.
} 


\begin{tabular}{|c|c|c|}
\hline Artículo & Requisito legal & Cumplimiento con mensaje de datos \\
\hline Artículo $6^{\circ}$. Escrito & $\begin{array}{l}\text { Información que } \\
\text { conste por escrito }\end{array}$ & $\begin{array}{l}\text { Si la información es accesible para } \\
\text { posterior consulta }\end{array}$ \\
\hline Artículo $7^{\circ}$ & $\begin{array}{l}\text { Presencia o ausen- } \\
\text { cia de firma }\end{array}$ & $\begin{array}{l}\text { Si permite identificación del iniciador } \\
\text { del mensaje mediante un método } \\
\text { confiable }\end{array}$ \\
\hline Artículo $8^{\circ}$. Original & $\begin{array}{l}\text { Información con- } \\
\text { servada en forma } \\
\text { original }\end{array}$ & $\begin{array}{l}\text { Si posee garantía confiable de conser- } \\
\text { vación de la integridad de la informa- } \\
\text { ción }\end{array}$ \\
\hline Artículo $9^{\circ}$. Integridad & \multicolumn{2}{|c|}{$\begin{array}{l}\text { Información considerada íntegra si ha permanecido completa } \\
\text { e inalterada }\end{array}$} \\
\hline $\begin{array}{l}\text { Artículo } 10 . \text { Admisibilidad } \\
\text { y Fuerza Probatoria }\end{array}$ & \multicolumn{2}{|c|}{$\begin{array}{l}\text { Los mensajes de datos son admisibles como medios de } \\
\text { prueba según fuerza probatoria concedida legalmente a los } \\
\text { documentos sin que pueda negársele eficacia, validez o fuer- } \\
\text { za probatoria por tratarse de mensaje de datos }\end{array}$} \\
\hline Artículo 12. Conservación & $\begin{array}{l}\text { Requisito de conser- } \\
\text { vación documental }\end{array}$ & $\begin{array}{l}\text { Si se conserva en el mismo formato y } \\
\text { si conserva la información que deter- } \\
\text { mine el origen, destino, fecha y hora } \\
\text { de envío o recepción }\end{array}$ \\
\hline Artículo 16. Atribución & \multicolumn{2}{|c|}{$\begin{array}{l}\text { Se entiende que el mensaje de datos proviene del iniciador } \\
\text { cuando ha sido enviando por este o por persona facultada } \\
\text { para ello o por un sistema programado automáticamente }\end{array}$} \\
\hline Artículo 17. Presunción & \multicolumn{2}{|c|}{$\begin{array}{l}\text { Se presume que el mensaje ha sido enviado por el iniciador } \\
\text { cuando se ha aplicado el procedimiento de envío previamen- } \\
\text { te acordado o cuando posee un método de identificación del } \\
\text { mensaje como propio }\end{array}$} \\
\hline Artículo 28. Firma Digital & Firma manuscrita & $\begin{array}{l}\text { Firma digital fijada en el mensaje } \\
\text { cuando es única, susceptible de } \\
\text { verificación, bajo control exclusivo } \\
\text { del usuario }\end{array}$ \\
\hline Artículo 35. Certificados & \multicolumn{2}{|c|}{$\begin{array}{l}\text { Certificado digital debe contener identificación del suscriptor, } \\
\text { clave pública del usuario, metodología para verificar la firma, } \\
\text { fecha de emisión y expiración del certificado }\end{array}$} \\
\hline
\end{tabular}

Cuadro \# 1: Creación propia.

\section{Análisis comparativo de la prueba electrónica y la prueba documental}

Dadas las particularidades de la prueba electrónica y las formalidades para que este medio de prueba sea efectivamente validado dentro de un juicio, se evidencia gran diferencia con lo explicitado inicialmente respecto de la prueba documental, en la medida en que los requisitos de validez, eficacia y 
valoración deben ser más específicos, cuya explicación lógica se encuentra en el hecho de corresponder a un medio igual o incluso más vulnerable ${ }^{45}$ que el documento físico, con más probabilidades de alteración, pues por su relevancia en el campo comercial y contractual, es blanco de ataques informáticos ${ }^{46}$, cuyas intrusiones se han incrementado ostensiblemente ${ }^{47}$, de manera que la prueba electrónica requiera de mayores medidas de protección tales como la encriptación, la utilización de firmas digitales ${ }^{48}$, estampas de tiempo y certificación de entidades avaladas para ello, a fin de cumplir con los requisitos de validez introducidos por la Ley № 527 de 1999. Por tanto, la seguridad que debe brindar este novedoso medio probatorio se debe poner de manifiesto ante el operador judicial, toda vez que una de las falencias ${ }^{49}$ de los documentos electrónicos es su alto grado de manipulación ${ }^{50}$, por lo cual la prueba electrónica conlleva implícita la necesidad de demostrar características particulares como las de autenticidad, fiabilidad, integridad o disponibilidad, mientras que en el caso de la prueba documental, a pesar de poder ser alterada, el proceso para ello es más complejo y técnico.

45 Al respecto, véase GambOA (2017), p. 83, que menciona que no existe un sistema de seguridad fiable, por lo que un sistema informático es un sistema vulnerable por su misma naturaleza. En igual sentido, Scotтı (2012), p. 60, refiriéndose al comercio electrónico, señala que "entre las desventajas, cabe señalar las dificultades para identificar a las partes que intervienen en la transacción, la falta de registro en papel que genera problemas probatorios $y$, en general, la falta de seguridad en las transacciones en desmedro de la protección de los consumidores". Asimismo, Dávara (2008), p. 35, sostiene que "Los negocios actuales se han ido creando una excesiva dependencia de los sistemas informáticos y se han hecho particularmente vulnerables debido, en gran parte, a las características propias del tratamiento telemático".

${ }^{46}$ CANO (2010), p. 335.

47 PeÑa (2003), p. 109: "Los hackers o intrusos de la red que violan las medidas de seguridad de los navegantes o de los propietarios de los sitios de internet son otra amenaza para la privacidad de los individuos y compañías que actúan en la red (...). Internet ha exacerbado la actividad de los hackers y ha obligado la creación de mecanismos de seguridad para luchar contra las intrusiones ilegales".

48 Al decir de Ortega (2010), p. 111: "De esta manera, critica, la normativa europea y española, en el sector, trata de dar seguridad tecnológica y no jurídica, pues se centra en la regulación de una firma electrónica segura pero no aporta una mayor seguridad jurídica ya que lo importante de una firma, sea electrónica, digital u ológrafa, no es la firma en sí sino la declaración que por medio de ella se expresa".

49 NieVA (2010), p. 319: "Los documentos multimedia tienen más posibilidades de ser modificados sin dejar rastro que los documentos tradicionales" haciendo referencia a los documentos electrónicos sin firma digital.

50 KAMINKER (2008), pp. 185-187, sostiene: "Puede afirmarse, sin embargo, que no existe la imposibilidad absoluta de averiguar la clave de un documento encriptado (...). Dato o hecho, incorporación a un elemento informático que permite su reproducción mediante un ordenador. Lo que da como resultado el documento informático, electrónico o digital, respecto de cuya situación es posible la modificación dolosa por quien ingrese al documento mediante ordenador". 
La eficacia del medio probatorio electrónico estará supeditada a la interpretación y comprensión que tenga el juez de la normativa y en particular de las peculiaridades y vicisitudes contenidas en la prueba electrónica, en el entendido de que, como se observó, en la práctica la prueba electrónica puede ser validada como un documento o relegada al grado de indicio, o sometida al extenuante y por lo general oneroso camino de la prueba pericial en donde, por obvias razones, los elementos de juicio contenidos en la prueba primigenia serán decantados por el criterio de un auxiliar de la justicia, y en este caso, ya no se tratará de prueba electrónica, sino de pericia informática, que incluso para algunos autores ${ }^{51}$ es el medio idóneo para darle verdadera eficacia a la prueba electrónica, lo que concedería ostensibles poderes al perito informático ${ }^{52}$. En otras palabras, la versión de los hechos que puede contener la prueba electrónica puede irse ensombreciendo en el proceso del iter probatorio, teniendo en cuenta que la prueba electrónica, como medio, habrá mutado a prueba documental, a prueba pericial o a prueba indiciaria.

Sin embargo, dado el auge del uso cotidiano y globalizado de las tecnologías de la información, surge el siguiente interrogante: ¿cómo asumir que la mayoría de los juicios suscitados con ocasión de esa interacción en medios electrónicos, deban ser aportadas al proceso o interpretadas por el juez mediante una prueba pericial? Ello sería tanto como afirmar que el perito informático ${ }^{53}$ indefectiblemente se convertirá en el asesor obligado de todo

51 Al respecto, afirma CANO (2010), p. 103, que el peritaje informático es una disciplina que convierte la información contenida en medios informáticos, en herramienta valiosa para ofrecer certeza o convencimiento al juez sobre unos hechos determinados. "Es así que a través del peritaje informático la prueba electrónica obtiene verdadera eficacia".

52 Morello (2001), p. 1: "En el mundo de las pruebas, al cambiar de centuria, se palpitan las pulsaciones de múltiples y polifacéticos replanteos, aperturas, ajustes teóricos, infinidad de proyecciones empíricas, irrupción de matices novedosísimos: la prueba científica, el poder cuasidecisorio del perito -o de los expertos en asuntos de alta complejidad-, la puesta al día del sistema de evaluación (en cuanto más dilatada y por cierto, afinada) que se dibuja en las reglas flexibles y sofisticadas de la sana crítica, el necesario, profundo y adecuado control de los hechos y de la prueba misma en el registro de la casación y el arribo de esa cuestión cardinal del proceso justo por el espléndido y siempre atrapante corredor de la doctrina de la arbitrariedad de sentencias".

${ }^{53}$ CANO (2010), p. 77: “(...) el peritazgo, a pesar de ser un medio eficaz para brindar certeza al juez sobre los hechos objeto del proceso, su práctica en el medio informático presenta problemas de costos, tiempo y probabilidades de éxito que llegan a dilatar el proceso. A su vez, y de no haber estándares para adelantar el procedimiento forense y valorar las pruebas recabadas en este proceso, se podría caer en insuficiencia en la resolución de eventuales litigios (...). Aunque el peritazgo y el indicio son mecanismos eficientes y eficaces a la hora de esclarecer los hechos de un caso, claramente éstos sufren problemas de costos, tiempo y especialidad que, en determinado momento, pueden llegar a dilatar la decisión del juez. Por tal motivo, y con el fin de proporcionarle una herramienta eficiente al operador jurídico, se hace necesario fijar unos parámetros de valoración de la prueba electrónica cuyo principal propósito consista en evitar que los hechos de un determinado caso sean valorados como 
juez, pues, vuelve y se repite, en un futuro que está a la vuelta de la esquina, la gran mayoría de juicios, al menos en el área civil o comercial, estarán permeados por hechos ocurridos en el uso de las tecnologías de la información o en el mundo virtual, cuya prueba de los hechos estará contenida en medios electrónicos.

No obstante, habrá quienes afirmen que lo relevante del proceso probatorio no es el medio a través del cual la representación de los hechos llegue al conocimiento del juez, sino precisamente la propia representación de los hechos contenida en cualquier medio. Sin embargo, dadas las particularidades antes vistas respecto de la prueba electrónica, la representación de los hechos suscitados en un medio electrónico o en el mundo virtual, introducidos al proceso a través de un medio probatorio como el documento, la pericia o el indicio, dejará por fuera del conocimiento del juez elementos de juicio valiosísimos que son, justamente, los que pueden contextualizar, ratificar o infirmar esa representación de hechos producida en un medio electrónico o virtual y contenida en un medio electrónico. Al respecto, opina Riofrío (2004): "algunos expertos como Browden opinan que la evidencia electrónica dejada por los mensajes de datos, incluso después de ser borrados, suelen ser mayor que la evidencia arrojada por los documentos tradicionales".

En este sentido, el grado de eficacia de la prueba electrónica, entendida como la capacidad probatoria de llevar al juicio la representación de la verdad de los hechos aunada al éxito de la prueba cuando las proposiciones sobre los hechos que se declaran probadas son verdaderas ${ }^{54}$, difiere de la eficacia probatoria conferida a la prueba documental y a la prueba pericial.

Y en esta misma línea, el principio de inmediación quedará supeditado igualmente al manejo que procesalmente se le conceda al medio probatorio, pues es totalmente diferente el hecho de que el juez cuente con la infraestructura tecnológica necesaria, así como con los elementos conceptuales suficientes para tener contacto directo con la prueba electrónica, a que su manipulación esté diferida a un perito auxiliar, cuya percepción obviamente será diferente a la del operador judicial. Asunto este que no es común en los documentos físicos, en los que esporádicamente se presentará este tipo de situaciones, mayormente en los eventos de tachas de falsedad. De esta manera, podría ser muy recurrente la presencia del perito informático dentro del proceso civil, si se tiene en cuenta que un gran número de procesos tendrán el mensaje de datos dentro de su acervo probatorio, dado que, como se manifestó al inicio

meros indicios o mediante peritazgos largos y costosos y, por lo tanto, lograr que el juez los admita como elementos formales".

${ }^{54}$ FeRRER (2007), p. 31. 
del presente análisis, un número significativo, y en crecimiento exponencial, de conflictos intersubjetivos se presentan en el ámbito virtual o electrónico. Ello implicaría que la prueba electrónica estuviera más ligada a la prueba pericial que a la prueba documental, a tal punto que algunas investigaciones le dan tratamiento de prueba compleja o mixta a la prueba electrónica, en tanto que requiere de otros medios probatorios para obtener toda su fuerza probatoria, lo que quita más peso a la equivalencia funcional entre prueba electrónica y prueba documental.

De otro lado, la originalidad del medio probatorio, en cuanto a la prueba electrónica, ha tenido disparidad de criterios; así:

Para la prueba documental se tiene que el artículo 244 del Código General del Proceso establece la forma de determinar la autenticidad de un documento ${ }^{55}$.

Para el documento electrónico, algunos autores ${ }^{56}$ manifiestan que el original es el medio magnético en donde se conserva y cualquier reproducción es copia, mientras que, para otros más vanguardistas, los documentos electrónicos son todos originales, incluyendo sus representaciones o copias, siempre y cuando conserven su formato primigenio y su contenido no sea alterado: "En el 'mundo' digital no se puede entender como documento original únicamente aquel en el que por primera vez se consigna la información, principalmente porque en la práctica el destinatario de un documento enviado vía electrónica recibe una copia y el remitente se queda con el que, en el contexto tradicional, conocemos como original" 57 .

A manera de ejemplo, un correo electrónico que se reciba en un ordenador personal (receptor) proveniente de x persona (emisor) tendrá las mismas características en cuanto a originalidad, integridad, etc., que el correo que se conserva en el computador o dispositivo de la persona que lo envió, de tal manera que ambos son originales.

\footnotetext{
${ }^{55}$ Ley No 1.564, de 2012, artículo 244. Documento Auténtico: "Es auténtico un documento cuando existe certeza sobre la persona que lo ha elaborado, manuscrito, firmado, o cuando exista certeza respecto de la persona a quien se atribuya el documento. Los documentos públicos y los privados emanados de las partes o de terceros, en original o en copia, elaborados, firmados o manuscritos, y los que contengan la reproducción de la voz o de la imagen, se presumen auténticos, mientras no hayan sido tachados de falso o desconocidos, según el caso (...). Los documentos en forma de mensaje de datos se presumen auténticos".

56 Al respecto, Rıofrío (2008), p. 109, menciona: “El problema en el mundo informático es que el original de un documento electrónico solo puede ser aquel que está archivado en el computador donde se lo ha digitado o creado. Para producir en el proceso un documento electrónico original, in stricto sensu, sería necesario incorporar a los autos la computadora donde se creó el documento".
}

57 CANo (2010), p. 15. 
Ahora bien, piénsese en el caso de contar con un programa administrador de correo electrónico, en el que una persona utiliza tanto el computador de su oficina como el personal de su casa, y aún en su tableta personal y en su teléfono inteligente, en todos los dispositivos se recibe el mismo correo electrónico enviado por la persona x. Ello significará que el receptor tendrá cuatro correos electrónicos originales, uno en cada dispositivo, siempre y cuando no los haya alterado y los conserve en su formato original, de manera tal que si este receptor pretende aportar tal correo electrónico a un proceso, bastará con hacer una copia desde cualquiera de los cuatro dispositivos electrónicos y allegarla al juzgado, ya sea en unidad de CD, o en USB, o en cualquier medio electrónico disponible, con lo cual garantizará que la prueba electrónica va a ser aportada en original.

Sin embargo, piénsese en el mismo caso, pero bajo la óptica restrictiva anterior que hace referencia a un único documento electrónico original; en tal evento, el original del correo electrónico solo se conservaría en el equipo desde donde fue transmitido, lo que haría casi imposible su aportación en formato original al proceso, máxime cuando el dispositivo de salida puede estar ubicado en cualquier rincón del planeta. Pero aún más, con el nuevo auge de los centros remotos de archivo de documentos, comúnmente denominados "nube virtual", se ha popularizado la práctica en la que cualquier persona puede tener una casilla "virtual" en donde puede almacenar cualquier tipo de información, cuyo dispositivo físico es propiedad del operador de la "nube" y cuya ubicación en el planeta es desconocida.

En este evento, ¿cómo podría accederse al original del documento electrónico? Máxime cuando los nuevos softwares incluyen la posibilidad de realizar un backup, en ocasiones de forma automática, de toda la información contenida en un computador de manera imperceptible, "en segundo plano", de manera tal que en cualquier momento se pueda acceder a la información almacenada en la "nube" sin disponer de ella físicamente o mediante un dispositivo determinado. Ello significa que la teoría del documento electrónico original, ya sea primigenio o reproducido, está más a tono con las nuevas realidades informáticas; así lo ratifica la Uncitral, según lo manifiesta el profesor Jeimy Cano: "Sobre este punto, la misma Uncitral señaló en la nota explicatoria de la Ley Modelo sobre Comercio Electrónico: [...] 'si por "original" se entiende el soporte en el que por primera vez se consigna la información, sería imposible hablar de mensaje de datos "originales", pues el destinatario de un mensaje de datos recibe siempre una copia del mismo'"158.

58 CANO (2010), p. 15. 
Contrastando ello con la prueba documental, se tiene que el artículo 246 del Código General del Proceso reguló el tema disponiendo la presunción de autenticidad de las copias al establecer que "Las copias tendrán el mismo valor probatorio del original, salvo cuando por disposición legal sea necesaria la presentación del original o de una determinada copia. Sin perjuicio de la presunción de autenticidad, la parte contra quien se aduzca copia de un documento podrá solicitar su cotejo con el original, o a falta de este con una copia expedida con anterioridad a aquella (...)".

Ello significa que si las copias físicas de los documentos físicos obtienen la presunción de autenticidad, en virtud del principio de equivalencia funcional se tendrá indefectiblemente que las copias de los documentos electrónicos también gozarán de tal presunción, con lo cual se torna en bizantina la discusión de la originalidad de las reproducciones de un documento electrónico, pues igual tendrán el mismo valor jurídico.

Más aún, el mismo Código General del Proceso, en su artículo 247, establece el valor probatorio de los mensajes de datos; así: "Serán valorados como mensajes de datos los documentos que hayan sido aportados en el mismo formato en que fueron generados, enviados, o recibidos, o en algún otro formato que lo reproduzca con exactitud. La simple impresión en papel de un mensaje de datos será valorada de conformidad con las reglas generales de los documentos".

Ahora, si la simple impresión en papel de un mensaje de datos tiene la fuerza probatoria de un documento que, como ya se vio, goza de presunción de autenticidad, los requisitos legales de aportar el mensaje de datos en su formato original, de identificar a su iniciador, de verificar su inalterabilidad, etc., ¿quedan en entredicho? Máxime cuando, según la ley, las copias de un documento tienen el mismo valor probatorio del original.

Concatenando lo anterior con los elementos de la prueba documental, el autor Xavier Abel Lluch $^{59}$ afirma que doctrinariamente se han establecido cuatro elementos principales en las pruebas documentales: i. El soporte, ii. El contenido, iii. El autor, y iv. La firma y fecha. Asimismo, afirma este autor que estos cuatro elementos también deben predicarse de la prueba electrónica, por lo cual, para efectos prácticos, y retomando a Xavier Abel, a continuación, se observa un paralelo, elaborado por este autor, entre estos cuatro elementos en uno y otro medio probatorio:

59 LLuCh y Picó I JunOY (2011), p. 37. 


\begin{tabular}{|c|l|l|}
\hline Elemento & \multicolumn{1}{|c|}{ Prueba documental } & \multicolumn{1}{|c|}{ Prueba electrónica } \\
\hline El soporte & $\begin{array}{l}\text { Soporte físico, habitualmente el pa- } \\
\text { pel }\end{array}$ & $\begin{array}{l}\text { Soporte magnético, óptico, tales } \\
\text { como CD, USB, flash drive, etc. }\end{array}$ \\
\hline El contenido & $\begin{array}{l}\text { Anido documentado, habitualmente } \\
\text { tible por los sentidos }\end{array}$ & $\begin{array}{l}\text { El contenido puede separarse de su } \\
\text { soporte y requiere de una estruc- } \\
\text { tura lógica (software y hardware) } \\
\text { para accederse y ser perceptible } \\
\text { para los sentidos }\end{array}$ \\
\hline El autor & $\begin{array}{l}\text { No es quien materialmente lo crea, } \\
\text { sino a quien jurídicamente se le atri- } \\
\text { buye su formación }{ }^{60}\end{array}$ & $\begin{array}{l}\text { Requiere de los elementos técnicos } \\
\text { para individualizar e identificar a } \\
\text { su autor (firma electrónica-digital) }\end{array}$ \\
\hline Firma y fecha & $\begin{array}{l}\text { De acuerdo a las formalidades de } \\
\text { cada acto, se requerirá o no de fir- } \\
\text { ma y fecha para la eficacia del do- } \\
\text { cumento }\end{array}$ & $\begin{array}{l}\text { Usualmente se graba la fecha del } \\
\text { dispositivo generador; sin em- } \\
\text { bargo, existen las certificaciones } \\
\text { digitales de estampa de firma y } \\
\text { estampa de fecha que confieren } \\
\text { seguridad al documento. }\end{array}$ \\
\hline
\end{tabular}

Cuadro \# 2. Fuente: Lluch y Picó i Junoy (2011), p. $37^{60}$.

Pero, además, se pueden agregar otros elementos diferenciadores, como por ejemplo la forma en que se crean las pruebas electrónicas y las pruebas documentales, el contenido ${ }^{61}$, sea este representativo o declarativo, la forma de aportación al proceso, los métodos de comprobación de su autenticidad, cuyo contenido por extenso no alcanza a ser abordado en el presente texto, pero cuya pertinencia es palpable teniendo en cuenta que la falsedad documental es absolutamente disímil en la prueba documental y la prueba electrónica.

Abordando otro aspecto, al igual que la clasificación mencionada en el capítulo correspondiente a la prueba documental, los documentos electrónicos también se podrían clasificar en públicos y privados, auténticos y no auténticos (aunque ello se refiere básicamente a la condición de existencia o no de firma electrónica); en constitutivos o meramente probatorios (aunque aquí los meramente probatorios no alcanzarían el estándar de mensaje de datos contenido en la Ley $N^{\circ}$ 527/99), y queda en entredicho, dada la discusión antes analizada sobre el original, la reproducción y la copia del documento electrónico.

Sin embargo, al margen de lo anterior y dadas las particularidades de este medio de prueba, se pueden clasificar, según el decir de Xavier Abel Lluch ${ }^{62}$, en las siguientes categorías:

\footnotetext{
${ }^{60}$ LLUCH y Picó I JunOY (2011), p. 39.

${ }^{61}$ Parra (2014), p. 501.

${ }^{62}$ LLuCH y Picó I Junor (2011), p. 30.
} 


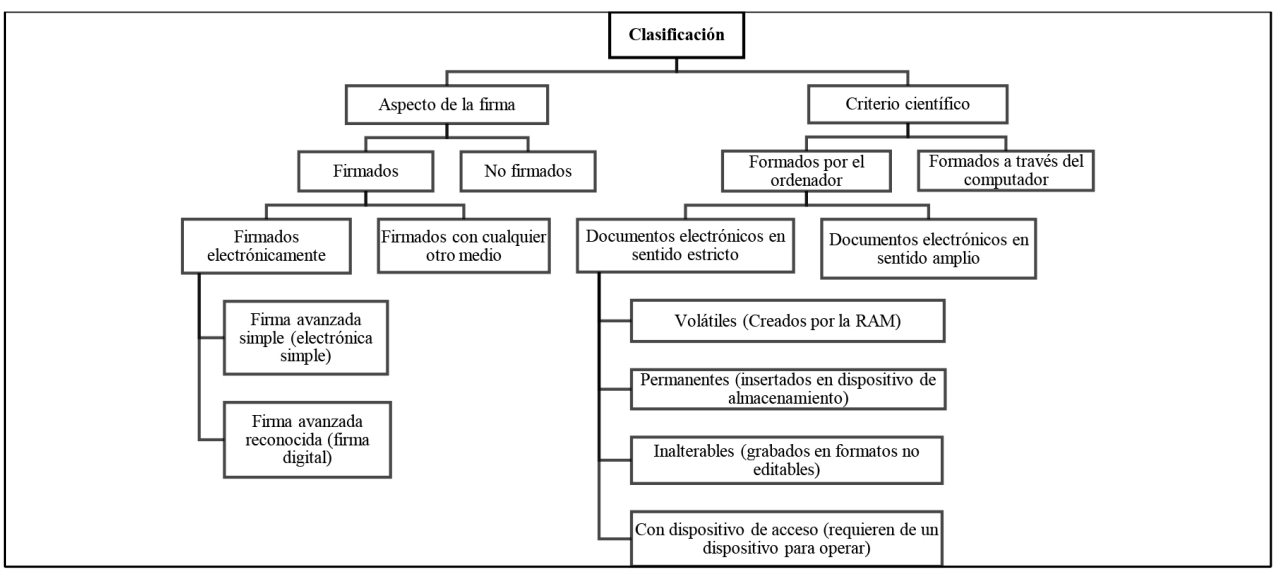

Cuadro \# 3. Creación propia tomando como fuente: Lluch y Picó i Junoy (2011), p. 30.

Resta agregar que otro tipo de clasificación es la reseñada por Julio José Elías $^{63}$, en cuanto a determinar tres tipos de documento electrónico: Printout: soporte de papel impreso, generado a través de medios informáticos; Imput: documento informático electrónico creado por datos almacenados en la memoria de un ordenador, y EDI: soporte de información electrónico formado mediante el intercambio de mensajes electrónicos.

Este panorama dista de lo explicado por autores tradicionales y antes citados respecto de la equivalencia entre la prueba documental y la prueba electrónica, por lo que cabe resaltar, para contrastar lo anteriormente expuesto, el paralelo que efectúa el profesor Parra Quijano, en donde concluye que los elementos de la prueba electrónica están perfectamente subsumidos o al menos equiparados a los elementos de la prueba documental, de manera tal que la prueba electrónica tan solo es una modalidad de prueba documental, lo que, bajo este panorama, aparece forzado.

En efecto, en lo anteriormente expuesto se vislumbra cómo uno y otro medio probatorio son disímiles en muchos de sus aspectos, lo que genera inquietud respecto a la apretada acomodación que se ha pretendido hacer de prueba electrónica como una modalidad de prueba documental. Y como prueba de ello, como si lo antes mencionado no fuera suficiente, y corriendo el riesgo de parecer redundante en temas ya abordados, resulta pertinente analizar un último elemento, pero que cronológicamente podría concebirse como uno inicial, que evidencia aún más la diferencia entre uno y otro medio probatorio.

${ }^{63}$ ElíAs (2008), p. 44. 
Doctrinariamente se ha hecho la distinción entre fuente y medio de prue$\mathrm{ba}^{64}$, designando el primer término a las circunstancias o características de la cosa inspeccionada, a los hechos o actos que se representan con los medios de prueba, y éstos, los medios de prueba, como el vehículo transmisor de la información, el puente entre la fuente y el proceso, al decir del profesor Ramírez Gómez. Esta fuente ha sido clasificada ${ }^{65}$ en fuente creadora (conocimiento originado en la propia fuente: confesión, testimonio y peritaje), fuente registro (pensamiento cristalizado en el registro: documentos, informes y reglas de la experiencia) y fuente indicadora (sentido referido a los hechos: indicios, inspección y conductas procesales).

Evidentemente, la prueba electrónica es un medio, pero a diferencia de la prueba documental, por sí misma puede ser fuente creadora, fuente registro y fuente indicadora, teniendo en cuenta que el mundo electrónico o virtual se torna en un plano en donde surgen relaciones interpersonales y, consecuencialmente, conflictos intersubjetivos de intereses, de manera tal que la prueba de los hechos estará contenida en un medio electrónico que puede ser: i. fuente de conocimiento por ser el escenario en donde nace y se produce esa interrelación "virtual"; ii. fuente registro por contener la cristalización o la evidencia de tal interrelación, y, a su vez, iii. fuente indicadora por poder reflejar lo sucedido con el conocimiento acaecido en el plano informático, por contener el registro de ello y además evidenciar la conservación, manipulación, alteración, transmisión, impresión, etc., de toda la información creada y almacenada en el medio electrónico. Esto no podría predicarse nunca de la prueba documental.

El problema surge, entonces, al momento de tratar de llevar al juez el medio Ilamado prueba electrónica, contentivo de la verdad de los hechos ocurridos, registrados e indicados en tal prueba, ante el imperativo legal de incorporarse como prueba documental y así mismo valorarse, o a lo sumo reescribirse mediante el medio de prueba pericial. No sería descabellado afirmar que la prueba electrónica, como fuente de conocimiento o contentiva de la representación de los hechos, no surte su eficacia innata al ser admitida, validada y valorada dentro del juicio civil, ya como prueba documental, ora como prueba pericial.

Ello porque, como se ha mencionado doctrinariamente, entre otros tantos aspectos de especial relevancia, el juez deberá valorar la prueba electrónica contemplando, mínimamente, los siguientes criterios: "a) atender a la naturaleza del documento; b) comprobar si viene firmado electrónicamente o no; c) el control del uso del conocimiento privado del juez; d) el recurso a la pericia

64 Ramírez (2008), p. 3.

${ }^{65}$ LazZaroni (1982), p. 52. 
informática, con carácter general; e) el examen del binomio hardware-software; f) las características del tipo de documento que se trate ${ }^{\prime \prime 66}$, todo ello siempre frente a los grandes requisitos de valoración del mensaje de datos: la integridad (inalterabilidad), la autenticidad (fiabilidad), la licitud y la rastreabilidad.

Nótese que, ante este panorama, la pericia informática tan solo hace parte de uno de los aspectos que deben ser valorados en el escenario de contemplar la prueba electrónica como autónoma, toda vez que el perito dará cuenta de la autenticidad de la prueba, de su alteración, conservación, emisión, firma, etc., en otras palabras, de aspectos técnicos o de forma de la prueba, pero no de su contenido, de la versión de los hechos que ella contiene, además de los otros datos relevantes intrínsecamente ligados a la prueba electrónica como los metadatos. De esta manera, la eficacia o fuerza probatoria de la prueba electrónica es ostensiblemente diferente de acuerdo con el tratamiento que se elija $\mathrm{o}$, mejor, de acuerdo con el medio de prueba que se disponga para ingresar los hechos al proceso, vuelve y se repite, que en todo caso estarán contenidos en un medio electrónico.

\section{La no equivalencia entre la prueba electrónica y la prueba documental}

"El arte del proceso no es esencialmente otra cosa que el arte de administrar las pruebas" ${ }^{\prime \prime}$.

La Comisión de las Naciones Unidas para el Comercio Electrónico estableció primigeniamente el criterio del "equivalente funcional" de la siguiente manera ${ }^{68}:$ "16. Así pues, la Ley Modelo sigue un nuevo criterio, denominado a veces 'criterio del equivalente funcional', basado en un análisis de los objetivos y funciones del requisito tradicional de la presentación de un escrito consignado sobre papel con miras a determinar la manera de satisfacer sus objetivos y funciones con técnicas del Ilamado comercio electrónico".

Con este principio de equivalencia funcional, la Cnudmi pretendió que ciertos requisitos exigidos de los documentos pudieran ser suplidos en el mensaje de datos, y principalmente referidos al contenido del mensaje, la inalterabilidad, la posibilidad de reproducción para las partes contratantes, la posibilidad de autenticación con firma y la viabilidad de poder ser presentado el mensaje ante las autoridades judiciales. Incluso, manifiesta la "Guía para la incorporación al derecho interno" de esta Ley Modelo, que en ocasiones la documentación

\footnotetext{
66 LLuCH y Picó I Junor (2011), p. 172.

67 Bentham (1971), p. 10.

68 Ley Modelo de la Cnudmi sobre Comercio Electrónico con la Guía para su incorporación al derecho interno (1998), p. 21.
} 
en medio electrónico podía ofrecer un mayor grado de fiabilidad, afirmación que, cerca de 20 años después, queda en tela de juicio teniendo en cuenta las vulnerabilidades antes mencionadas, que requieren para este medio de prueba, un mayor esfuerzo en cuanto a medidas de protección y de seguridad, que dicho sea de paso no pueden ser estáticas, sino dinámicas en tanto el desarrollo de nuevas tecnologías abrigan incluso el campo de los delitos informáticos ${ }^{69}$.

Es importante resaltar que la misma Cnudmi reconoce que el mensaje de datos no es equivalente funcional de un documento en papel en estricto sentido, pero aun así, para efectos de facilitar el comercio electrónico, este "criterio flexible" imperó y fue retomado por la mayoría de las legislaciones de Latinoamérica.

No obstante lo anterior, no podría afirmarse por este solo hecho que todo mensaje de datos se equipara a un documento físico o escrito, pues para ello, necesaria y fundamentalmente, deberá ser accesible en el tiempo para su posterior consulta. Tampoco significa lo anterior que todo mensaje de datos o documento electrónico tenga plena fuerza probatoria, pues al igual que con la prueba documental, deberán validarse y valorarse ${ }^{70}$ sus características en cuanto a integridad, autenticidad, integridad, originalidad, autoría, no repudio, confidencialidad, veracidad.

El legislador colombiano, al igual que la mayoría de los entes legislativos de América Latina, basado en las reglas internacionales trazadas por la Naciones Unidas, entendió que el vehículo legal capaz de trasladar la prueba electrónica del mundo virtual al proceso judicial era justamente este principio de equivalencia funcional.

La Corte Constitucional se pronunció con respecto a la exequibilidad de la Ley $\mathrm{N}^{\circ} 527$ de 1999, manifestando, justamente sobre la equivalencia funcional, lo siguiente ${ }^{71}$ : "El proyecto de ley, al igual de la Ley Modelo, sigue el criterio de los 'equivalentes funcionales' que se fundamenta en un análisis de los propósitos y funciones de la exigencia tradicional del documento sobre papel, para determinar cómo podrían cumplirse esos propósitos y funciones con técnicas electrónicas. Se adoptó el criterio flexible de 'equivalente funcional', que tuviera en cuenta los requisitos de forma fiabilidad, inalterabilidad y rastreabilidad, que son aplicables a la documentación consignada sobre papel, ya que los mensajes de datos por su naturaleza no equivalen en estricto sentido a un documento

\footnotetext{
69 CANO (2010), p. 105.

70 Riofrío (2004), p. 91.

71 Corte Constitucional de Colombia, Sentencia C-662 de 8 de junio de 2000, en concordancia con la Sentencia C-831 de 2001 de la misma corporación, que extiende la constitucionalidad de la Ley N 527 de 1999 incluso en caso de actuaciones del Estado a través de mensajes de datos, como equivalente del documento escrito.
} 
consignado en papel. En conclusión, los documentos electrónicos están en capacidad de brindar similares niveles de seguridad que el papel y, en la mayoría de los casos, un mayor grado de confiabilidad y rapidez, especialmente con respecto a la identificación del origen y el contenido de los datos, siempre que se cumplan los requisitos técnicos y jurídicos plasmados en la ley".

Se debe resaltar que, pese a que la corte equipara los documentos electrónicos con los documentos consignados en papel, también destaca que los mensajes de datos, dada su naturaleza, no equivalen en estricto sentido a un documento consignado en papel, dándole incluso al documento electrónico mayores niveles de seguridad que el documento plasmado en papel, obviamente cuando se observan los requisitos técnicos y jurídicos exigidos en la ley.

Es innegable, así, que un primer avance de la Ley No 527 de 1999 fue el de consagrar el principio de equivalencia funcional, tal como lo concibió Naciones Unidas, de forma tal que, en virtud de esta regla, la información contenida en un medio electrónico pudiera ser aportada al proceso como prueba judicial y someterse a las etapas correspondientes del iter probatorio; sin embargo, tal norma se expidió en un momento histórico en el que las tecnologías de la información apenas estaban tocando las puertas de la jurisdicción y de los procesos jurisdiccionales, al menos en civil, de modo que para evitar que las relaciones comerciales establecidas en forma electrónica se quedaran sin escenario jurídico que pudiera resolver válidamente los conflictos que allí se suscitaran, la respuesta "rápida" o al menos efectiva, según la concepción de las Naciones Unidas, fue la invención del referido principio de equivalencia funcional, con lo cual no era necesario el desarrollo hermenéutico y procedimental de la teoría de la prueba electrónica, sino simplemente bastaba con acudir a las teorías clásicas que contemplaban la posibilidad de que "cualquier otro medio contentivo de información o lenguaje humano" pudiera ser admitido en el juicio como prueba documental.

Pero, si esta era la voluntad del legislador, ¿por qué razón no se reguló desde un principio el mensaje de datos como una variable de la prueba documental, y no como un equivalente funcional de ella? Es claro que la referencia de prueba documental para la prueba electrónica o, dicho de otro modo, el método de subsunción de la prueba electrónica al ordenamiento procesal civil que se efectúa mediante el principio de equivalencia funcional establecido en el artículo 10 de la Ley № 527 de $1999^{72}$, implícitamente le otorga cierta

\footnotetext{
72 Ley № 527 de 1999, artículo 10: "Los mensajes de datos serán admisibles como medios de prueba y su fuerza probatoria es la otorgada en las disposiciones del Capítulo VIII del Título XIII, Sección Tercera, Libro Segundo del Código de Procedimiento Civil. En toda actuación administrativa o judicial, no se negará eficacia, validez o fuerza obligatoria y probatoria a todo tipo de información en forma de un
} 
independencia al mensaje de datos de la prueba documental, como si de una criatura naciente se tratara, cuya emancipación fuera diferida en el tiempo por requerir tanto de la maduración propia del sistema legal de prueba como de la misma prueba electrónica.

Es así como dentro de la Ley $N^{\circ} 527$ de 1999 se identifican tres equivalentes funcionales que permiten equiparar, por fuerza vinculante, ambos medios de prueba:

1. Equivalencia funcional del escrito: "Artículo $6^{\circ}$. Escrito. Cuando cualquier norma requiera que la información conste por escrito, ese requisito quedará satisfecho con un mensaje de datos, si la información que éste contiene es accesible para su posterior consulta".

2. Equivalencia funcional de firma: "Artículo $7^{\circ}$. Firma. Cuando cualquier norma exija la presencia de una firma o establezca ciertas consecuencias en ausencia de la misma, en relación con un mensaje de datos, se entenderá satisfecho dicho requerimiento si:

- Se ha utilizado un método que permita identificar al iniciador de un mensaje de datos y para indicar que el contenido cuenta con su aprobación.

- Que el método sea tanto confiable como apropiado para el propósito por el cual el mensaje fue generado o comunicado".

3. Equivalente funcional del original: "Artículo $8^{\circ}$. Original. Cuando cualquier norma requiera que la información sea presentada y conservada en su forma original, ese requisito quedará satisfecho con un mensaje de datos, si:

- Existe alguna garantía confiable de que se ha conservado la integridad de la información, a partir del momento en que se generó por primera vez en su forma definitiva, como mensaje de datos o en alguna otra forma;

- De requerirse que la información sea presentada, si dicha información puede ser mostrada a la persona que se deba presentar".

Nótese, entonces, que estos tres equivalentes entrarán a formar parte del juicio de validez como segundo estadio del iter probatorio para esta clase de pruebas; no obstante, el juicio de validez que se debe efectuar con la prueba documental no es el mismo que se plantea para la prueba electrónica.

De otro lado, según lo explica Xavier Abel Lluch, la doctrina española ha condicionado la equivalencia funcional entre la prueba documental y la electrónica al cumplimiento de los siguientes requisitos ${ }^{73}$ : i. Que se pueda hacer legible mediante sistemas de hardware y software; ii. El contenido del documento emitido por el autor debe ser igual al entregado al receptor; iii. Que sea posi-

mensaje de datos, por el sólo hecho que se trate de un mensaje de datos o en razón de no haber sido presentado en su forma original".

73 LLUCH y Picó I JunOY (2011), p. 110. 
ble su conservación y recuperación; iv. Que el documento electrónico pueda traducirse al lenguaje convencional; v. Que se puedan identificar los sujetos participantes en el documento; vi. Que la autoría del mismo pueda ser atribuida a una determinada persona, y vii. Que el documento reúna las condiciones de autenticidad y fiabilidad, así como los sistemas utilizados para su certificación o incorporación de firma electrónica.

En principio, el juicio de admisibilidad, como primer filtro para la inserción de la prueba electrónica al proceso jurisdiccional, deberá efectuarse con base en lo que la Ley № 527 de 1999 establece como mensaje de datos, de manera tal que una prueba contenida en un medio electrónico será admisible en un juicio si cumple los siguientes primeros estándares:

- Si la información contenida en la prueba es generada, enviada, recibida, almacenada o comunicada por medios electrónicos, ópticos o similares, tales como el Intercambio Electrónico de Datos (EDI), internet, el correo electrónico, el telegrama, el télex o el telefax.

- Si la información consignada en un mensaje de datos es íntegra; es decir, si esta ha permanecido completa e inalterada, salvo la adición de algún endoso o de algún cambio que sea inherente al proceso de comunicación, archivo o presentación.

- Si cumple con el grado de confiabilidad requerido, que será determinado a la luz de los fines para los que se generó la información y de todas las circunstancias relevantes del caso (emisión, recepción, atribución, origen, concordancia, etc.).

Pero, además de lo anterior, en casos en los que la ley exige la presencia de una firma, o la conservación en formato original del documento, o de conservación para posterior consulta, la ley establece algunos requisitos adicionales, verificables en el texto de la misma normativa, caso en el cual tales requisitos harán parte de la lista de chequeo para el juicio de admisibilidad. Todos estos requisitos, en manera alguna se exigen de la prueba documental, máxime que, tal como se evidenció al inicio de este escrito, la ley concede plenos efectos probatorios incluso a las simples copias de la prueba documental.

Finalmente, para el juicio de valoración, además de la sana crítica, el artículo 11 de la Ley № 527 de 1999 incorpora unos indicadores, que se convierten en uno de los retos que debe afrontar la administración de justicia, pues el juez deberá tener en cuenta lo siguiente: i. "La confiabilidad en la forma en que se haya generado, archivado o comunicado el mensaje". Para ello indefectiblemente deberá tenerse acceso a los metadatos ${ }^{74}$ de la prueba electrónica, es decir, a la

${ }^{74}$ Senso y De La Rosa Piñero (2003): Metadata: Información adicional no visible, que hace parte integral de un documento electrónico en su fase primigenia, y, según Tim Berners-Lee, pueden ser: "El primero 
evidencia propia del documento, en donde puede verse el origen y la forma de transmisión de la información. ii. "La confiabilidad en la forma en que se haya conservado la integridad de la información", es decir, se deberá verificar la autenticidad u originalidad del documento, pero también se debe analizar el proceso de conservación, asuntos estos que no se vislumbran a simple vista. iii. "La forma en la que se identifique a su iniciador", y es aquí en donde juega un papel importante el tipo de firma que se haya anexado al mensaje de datos, pues si se trata de firma digital, bastará con la certificación digital de la entidad certificadora para identificar al autor o iniciador, salvo -claro está- el proceso de tacha. Si se anexó firma electrónica, la carga de la prueba en la demostración de los anteriores elementos correrá por cuenta de quien pretenda hacer valer el documento electrónico, sin que quepa la dinamización de tal carga ${ }^{75}$, teniendo en cuenta que solo la firma digital goza de la presunción legal de autenticidad. En este punto cabe recordar que doctrinariamente se ha establecido la doble dimensión implícita en la carga de la prueba, correspondiéndole al juez fallar con las pruebas que se hayan practicado, aunque sean insuficientes, lo que se conoce como la regla de juicio ${ }^{76}$, por lo que, frente a la prueba electrónica, cobra mayor vigencia esta regla de juicio toda vez que este medio de prueba puede ofrecer al juez un mayor acercamiento a la versión de los hechos que le proponen las partes, lo cual obviamente dependerá del medio en que la prueba electrónica Ilegue al proceso. iv. "Cualquier otro factor pertinente", referido a asuntos como el método de creación del mensaje de datos, pero también concernientes a los archivos adjuntos en caso de existir; el formato utilizado, el software, versión, en fin, cualquier elemento adicional al mensaje de datos, tales como los metadatos, que pueden ser bastantes pero imperceptibles u ocultos y que pueden aportar elementos de juicio de relevancia para la decisión del juez.

Nótese entonces que, lejos de la forma en que se presenta el iter probatorio de la evidencia documental, en relación con las pruebas electrónicas, dadas sus particularidades, las exigencias del juez son mayores para su juicio de admisibilidad y de valoración probatoria, razones por las cuales en la práctica se acude a un perito experto en la materia o simplemente se degradan al nivel de prueba indiciaria.

\footnotetext{
de ellos es el que se encuentra dentro del documento mismo. El segundo es el que se produce durante una transferencia HTTP (HyperText Transfer Protocol). El último es más difícil de encontrar, ya que el metadato se utiliza cuando se consulta en otro documento (para comprobar si se puede acceder a él -o al sitio web-, verificar derechos de autor....".

${ }^{75} \mathrm{Al}$ respecto de la carga dinámica de la prueba y sus implicaciones con relación al debido proceso y derecho de defensa, véase Palomo (2013), p. 460.

76 Palomo (2013), p. 452.
} 
En este punto, se debe alcanzar claridad en lo siguiente: si la prueba electrónica, además de ser medio de prueba, puede constituirse en i. fuente creadora, ii. fuente registro y iii. fuente indicadora, la equivalencia funcional concedida por la ley para ser admitida, validada y valorada en el juicio civil tan solo estaría equiparando dos medios de prueba (prueba electrónica y prueba documental), lo que dejaría a la verdad de los hechos contenida en la prueba electrónica concebida como fuente, por fuera de tal equivalencia y, por ende, del juicio civil, es decir, i. como conocimiento originado en la propia fuente, ii. como fuente registro o elemento cristalizador del registro del hecho, y iii. como fuente indicadora. En otras palabras, la información alojada en la prueba electrónica, tal como los metadatos, los registros, los sistemas de verificación, los atributos y, en fin, lo que se podría llamar la hoja de vida o historia clínica del medio probatorio, quedarían por fuera del proceso, dado que no llegarían a manos del juzgador o fallador y, por lo tanto, no podrían ser objeto de valoración probatoria.

Incluso, la información contenida en una prueba electrónica podría desvirtuar o confirmar los hechos que precisamente se pretenden demostrar con tal medio probatorio, lo que resultaría a todas luces determinante y contundente para el juez al momento de efectuar el juicio de valor; es más, a esta clase de información se le ha conocido como la prueba de la prueba electrónica (metadatos), que también, vale advertir, puede ser manipulable, en virtud de la vulnerabilidad de los sistemas informáticos. Al respecto, el abogado y especialista en derecho informático y tecnologías de la información Rafael Perales Cañete ${ }^{77}$, en un artículo evidenció de qué manera incluso los metadatos de una prueba electrónica pueden ser alterados, lo que, a los ojos de alguien sin la experiencia y el conocimiento suficientes, podría generar convencimiento de hechos que jamás ocurrieron o que están manipulados y tergiversados. A manera de ejemplo, piénsese en una fotografía tomada con una cámara analógica y con una cámara digital; la primera, luego de revelada, podrá evidenciar una imagen, al igual que la imagen que ofrece la fotografía digital, pero a diferencia de la primera, la fotografía digital, vista como prueba electrónica, puede contener, además de la imagen, metadatos que indiquen el lugar preciso y la fecha y hora en que fue tomada, el tipo de dispositivo que la tomó, la dirección IP desde donde se envió, la fecha de origen del archivo, fecha de modificación, fecha de última apertura, etc., lo que a todas luces se convierte en información de suma utilidad en un determinado juicio, datos estos que ni por asomo podrían deducirse de la fotografía analógica.

77 Perales (2016), p. 108. 
Estas características abordadas (los estándares de admisibilidad, la vulnerabilidad, las características o principios de valoración, la información oculta pero integral de la prueba), detrás de la prueba electrónica, permiten afirmar que este medio de prueba no es funcionalmente equivalente a la prueba documental, y lo que otrora se admitiera como un logro y un avance de la ciencia jurídica, en la actualidad se convierte en un arma de doble filo para el juez, que en última instancia se ve abocado a admitir, validar y valorar una prueba electrónica que dista enormemente de la prueba documental, colocando en peligro la tutela judicial efectiva, pues la verdad de los hechos contenidos en la prueba electrónica no podrá ser objeto de un correcto juicio de valoración probatoria.

Para finalizar, cabe mencionar lo referenciado por el tratadista Miguel Temboury Redondo refiriéndose a la Ley de servicios de la sociedad de la información y del comercio electrónico de la Comunidad Económica Europea, respecto del documento electrónico ${ }^{78}$ : "Cabe plantearse, por otro lado, si lo que se ha producido es una evolución del concepto o una tradicional indefinición del mismo. Dicho en otras palabras, es posible que los problemas que se presentan hoy en día a la hora de determinar el valor que debe atribuirse a los nuevos soportes documentales supongan que las definiciones hasta ahora dadas del documento no eran sino una aproximación empírica (y en consecuencia necesariamente ligada a las formas de documentos hasta entonces existentes) al verdadero concepto y a la verdadera naturaleza de los documentos".

\section{Conclusiones}

1. El derecho informático tiene su desarrollo en el mundo globalizado, que desencadenará el surgimiento de nuevos conflictos judiciales basados en pruebas informáticas.

2. La concepción primigenia de prueba documental ha permanecido inalterable, salvo la pretendida inclusión de una nueva modalidad de documento: el documento electrónico o documento multimedia; sin embargo, la prueba electrónica como medio probatorio dista enormemente de lo que se conceptualiza y regula como prueba documental, tanto en su validez como en su eficacia y en su valoración judicial, tal como se observó en el acápite de la prueba documental.

3. La prueba electrónica contiene particularidades, vicisitudes, que incluso casi 22 años después de haber ganado terreno en los estrados judiciales a partir del principio de equivalencia funcional, en la actualidad no han sido estudiadas a fondo por tratarse de un medio en constante evolución, por lo cual mal podría equipararse funcionalmente a un medio de prueba que desde antaño está

${ }^{78}$ Mateu (2003), p. 485. 
delimitado, regulado y legalizado con formas propias, muy distantes a las formas de la prueba electrónica, según lo analizado en el apartado referente a esta.

4. Los motivos que tuvo inicialmente la CNUDMI para promover el principio de equivalencia funcional entre el mensaje de datos y la prueba documental, hoy han pasado a otro plano, que requiere incluso de un mayor desarrollo, teniendo en cuenta que lo que otrora fuera una prueba con mayor grado de seguridad y eficacia que la prueba documental, hoy se torna en un medio probatorio de cuidado y especial atención, que merece un tratamiento autónomo que a la postre permitirá al operador judicial efectuar un correcto juicio de valor a fin de tomar una decisión justa, con lo cual garantiza en gran medida la tutela judicial efectiva.

5. No existe equivalencia funcional entre la prueba electrónica y la prueba documental, y este reconocimiento lo efectúa la misma Cnudmi desde su exposición de motivos, criterio incluso ratificado por la Corte Constitucional colombiana en sentencia C-662 de 8 de junio de 2000, al examinar la exequibilidad de la Ley $N^{\circ} 527$ de 1999; no obstante, estas instituciones insisten en el principio de equivalencia, pero por motivos de eficacia y eficiencia respecto del ordenamiento judicial, para dirimir conflictos suscitados en el ámbito electrónico.

6. Al no existir, al menos en el tiempo presente, equivalencia funcional, el principio deja de operar, lo que implica la necesidad imperiosa de desarrollar la teoría de la prueba electrónica como medio de prueba autónomo e independiente de la prueba documental y de la prueba pericial.

7. Solo así el juez podrá garantizar la tutela judicial efectiva en tanto pueda efectuar un correcto juicio de valor de este novedoso medio de prueba, plasmado en la decisión justa.

8. Finalmente, en la medida en que el derecho procesal contemporáneo garantice un correcto juicio de valor por parte del funcionario judicial en los conflictos intersubjetivos que se le propongan con fundamento en pruebas electrónicas, se verificará una congruencia absoluta entre el fin de este derecho procesal contemporáneo y la recomposición del conflicto social, surgido con ocasión del uso de las tecnologías de la información, dando como resultado una efectiva administración de justicia, humana, garantista y constitucional.

\section{BiBLIOGRAFÍA CITADA}

BeCERRA LeÓN, Henry (2015): "Documento electrónico y título valor electrónico". Disponible en: http://portalweb.ucatolica.edu.co/easyweb/files/105_16217_ documento-electronico.pdf [visitado el 26.05.18].

Bentahm, Jeremías (1971): Tratado de las pruebas judiciales (Buenos Aires, Ediciones Jurídicas Europa-América), Volumen I. 
Cano Martínez, Jeimy (2010): El peritaje informático y la evidencia digital en Colombia (Bogotá, Ediciones Uniandes).

Comisión de las Naciones Unidas para el Derecho Mercantil Internacional (1998): "Ley Modelo de la Cnudmi sobre Comercio Electrónico Guía para su incorporación al derecho interno". Disponible en: http://www.uncitral.org/ pdf/spanish/texts/electcom/05-89453_S_Ebook.pdf [visitado el 24.05.18].

Dávara Rodríguez, Miguel (2008): Manual de derecho informático, Décima Edición (Pamplona, Aranzadi).

De PINA, Rafael (1942): Tratado de las pruebas civiles (Ciudad de México, Editorial Porrúa).

Elías Baturones, Julio (2008): La prueba de documentos electrónicos en los tribunales de justicia (Valencia, Tirant lo Blanch).

ENRÍQuez Pérez, Isaac (2008): "Globalización y privatización: ¿Dos caminos rumbo a la desnacionalización integral?", en: Revista Académica de Economía. Disponible en: http://www.eumed.net/cursecon/ecolat/mx/iep-gp.htm [visitado el 19.11.17], pp. 1-7.

FerRer BetTRÁn, Jordi (2007): La valoración racional de la prueba (Madrid, Marcial Pons).

Gascón Abellán, Marina (2010): Los hechos en el derecho, Tercera Edición (Madrid, Marcial Pons).

Gamboa Bernate, Rafael (2017): "Computación en la nube, due diligence: Responsabilidad, territorialidad y desafíos para la administración de justicia", en: AA. VV., Justicia y TIC (Bogotá, Legis S.A.).

Guasp Delgado, Jaime (1998): Derecho procesal civil (Madrid, Civitas).

KAMINKER, Mario E. (2008): "Reflexiones sobre la incidencia de los documentos electrónicos y con firma digital en el sistema general de los documentos", en: Arazi, Roland (Director), Prueba ilícita y prueba científica (Buenos Aires, Rubinzal y Culzoni Editores), pp. 177-198.

LazZaroni, Luis J. (1982): El conocimiento de los hechos en el proceso civil (Buenos Aires, Abeledo-Perrot).

Lıuch, Xavier Abel, y Pıcó I Junor, Joan (2011): La prueba electrónica, Serie estudios prácticos sobre los medios de prueba, Número 5 (Barcelona, Bosch Editores).

MANZINI, Vicenzo (1952): Tratado de derecho procesal penal (Buenos Aires, Ediciones Jurídicas Europa América), tomo III.

Meneses Pacheco, Claudio (2008): "Fuentes de prueba y medios de prueba en el proceso civil", en: Revista lus et Praxis (Vol. 14, № 2), pp. 43-86. 
Mteheran (2008): "Bios de un computador". Disponible en: http://mteheran.wordpress.com/2008/05/30/bios-de-un-computador/ [visitado el 02.17.2018].

Morello, Mario Augusto (2001): La prueba. Tendencias modernas, Segunda Edición (Buenos Aires, Abeledo-Perrot).

Moreno, Francisco (2008): "Lex mercatoria, Derecho de la globalización sin Estado". Disponible en: http://www.liberalismo.org/articulo/423/lex/mercatoria/derecho/globalizacion/estado/ [visitado el 18.11.17].

New York University (en línea): "Claude Shannon". Disponible en: http:// www.nyu.edu/pages/linguistics/courses/v610003/shan.html [visitado el 4.05.2018].

Nieva Fenoll, Jordi (2010): La valoración de la prueba (Madrid, Editorial Marcial Pons).

Ortega Díaz, Juan (2010): Contratación, notarios y firma electrónica (Bogotá, Ediciones Uniandes -Editorial Temis).

Palomo Vélez, Diego, y De La Oliva Santos, Andrés (2007): Proceso civil. Hacia una nueva justicia civil (Santiago, Editorial Jurídica de Chile), pp. 227-254.

Palomo Vélez, Diego (2013): "Las cargas probatorias dinámicas: ¿Es indispensable darse toda esta vuelta?", en: Revista lus et Praxis (Vol. 19, № 2), pp. 447-466.

PARRA QUIJANO, Jairo (2014): Manual de derecho probatorio, Decimoctava Edición (Bogotá, Ediciones El Profesional Ltda.).

Peña Valenzuela, Daniel (2003): "Responsabilidad y comercio electrónico. Notas sobre el daño y el riesgo en la sociedad de la información", en: $A A$. $V V$., El contrato por medios electrónicos (Bogotá, Universidad Externado de Colombia), pp. 161-186.

Perales Cañete, Rafael (2016): "Exiftool: ¿Los metadatos sirven de algo?", en: La prueba electrónica validez y eficacia procesal. Colección Desafíos Legales (e-Book). Disponible en http://derechomasinformatica.es/bitacora/exiftoollos-metadatos-sirven-de-algo/ [visitado el 24.05.18].

Piqueras INFANTE, Andrés (2008): “¿'Globalización' como nuevo imperialismo? Los intersticios de intervención de los sujetos antagónicos", en: Revista Theomai/Theomai Journal. Disponible en: http://revista-theomai.unq.edu. ar/Numero17/Piqueras.pdf [visitado el 19.11.17].

Ramírez Gómez, José (2004): Principios constitucionales del derecho procesal (Medellín, Señal Editora).

Ramírez Gómez, José (2008): La prueba documental, Octava Edición (Medellín, Señal Editora). 
Rincón CÁRDENAS, Erick (2015): Derecho del comercio electrónico y de internet, Segunda Edición (Bogotá, Legis Editores S.A.).

Riofrío Martínez-Villalba, Juan (2004): La prueba electrónica (Bogotá, Temis).

Rocha Alvira, Antonio (1990): De la prueba en derecho (Medellín, Biblioteca Jurídica Dike).

Scottı, Luciana Beatriz (2012): Contratos electrónicos (Buenos Aires, Eudeba).

Senso Ruiz, José A., y De La Rosa Piñero, Antonio (2003): "El concepto de metadato. Algo más que descripción de recursos electrónicos". Disponible en: http://www.scielo.br/pdf/ci/v32n2/17038.pdf/ [visitado el 26.05.18].

TARUFFO, Michelle (2006): Sobre las fronteras, Escritos sobre la justicia civil

(Traducc. Beatriz Quintero de Prieto, Bogotá, Editorial Temis S.A.).

TARuffo, Michelle (2008): La prueba (Madrid, Editorial Marcial Pons).

Temboury Redondo, Miguel (2003): "El documento electrónico", en: AA. VV.,

Derecho de internet, La Ley de Servicios de la Sociedad de la Información y de Comercio Electrónico, Segunda Edición (Navarra, Editorial Arazandi).

VISHINSKI, Andrés (1951): La teoría de la prueba en el derecho soviético (Buenos Aires, Ed. Pueblos Unidos).

\section{NORMAS JURÍDICAS CITADAS}

Decreto № 1.400 de 1970, Código de Procedimiento Civil, 6 de agosto de 1970. Ley Modelo de la Cnudmi sobre Comercio Electrónico, 12 de junio de 1996. Ley No 527 de 1999, Ley de Mensajes de Datos, Comercio Electrónico y Firmas

Digitales, 18 de agosto de 1999.

Ley No 1.564 de 2012, Código General del Proceso, 12 de julio de 2012.

\section{JURISPRUDENCIA CITADA}

Sentencia C-662 de 8 de junio de 2000, Corte Constitucional de Colombia, M.P. Fabio Morón Díaz.

Sentencia C-831 de 8 de agosto de 2001, Corte Constitucional de Colombia, M.P. Álvaro Tafur Galvis. 
